\title{
EDITORIAL
}

\section{Academic standing and publication}

\author{
Roger W. Byard ${ }^{1}$
}

Accepted: 7 December 2021 / Published online: 3 January 2022

(C) The Author(s), under exclusive licence to Springer Science+Business Media, LLC, part of Springer Nature 2021

Curiosity is the essence of human existence

Gene Cernan (1934-2017)

It is now over a decade since I took on the role of Editorin-Chief of Forensic Science Medicine and Pathology (Fig. 1) and it has been a great pleasure to see the journal develop and mature over this period, but now it is time to step aside and bring in new editors with new ideas. The focus of the journal has always been somewhat eclectic with the aim of providing a selection of interesting and diverse papers that would appeal not only to subspecialist practitioners but also to a general forensic readership. Research and observations powered by curiosity have been its life force. My role as Editorin-Chief has been extraordinarily well supported by the two senior editors, Prof Michal Tsokos and Dr John Hunsaker III, whose unstinting commitment has ensured nothing but the highest standards. In addition, the journal's progress would not have been possible without the extremely hard work and dedication of our Editorial Assistant, Melissa Walker, and our Executive Editor with Springer in New York City, Melissa Ramondetta, as well as all of our highly qualified board members and Springer technical staff. To all of these people I give my unqualified thanks and appreciation - it has been an enormous pleasure and honor to work with you.

Over the years I have reviewed more than 3,500 papers for the journal and have written various editorials and commentary pieces on publishing, particularly in forensics, and so have had an excellent opportunity to observe changing trends over time. While research in forensic fields has had a somewhat checkered past [1] it clearly has an important role to play [2], although each step of the publishing process is not without its difficulties [3]. One of the things that has recently struck me, however, is that assessing a researcher's academic standing in his or her particular field has become increasingly difficult.

Roger W. Byard

roger.byard@sa.gov.au

1 The Adelaide Medical School, The University of Adelaide, Adelaide, South Australia, Australia
For most of last century the evaluation of academic productivity and position was relatively uncomplicated. Researchers worked their way up in established universities and colleges, undertaking studies, and publishing the results in journals that were widely recognized in their particular area. A search through the printed pages of Index Medicus could easily identify those who were leading in their respective fields, confirmed by reading through hard copy editions of journals that all academic libraries subscribed to. However, computers, electronic databases and new methods of publishing have changed this forever, often with a loss of rigor in grammar, expression and writing style. For example, a review of 100 papers that were recently accepted for publication in Forensic Science Medicine and Pathology showed that a full $36 \%$ had errors in referencing that required correcting - and that these sadly were often repeated on resubmission [4].

The advent of ultra-fast turnaround predatory publishing has also meant that publication space can now be simply bought, so that the quality and veracity of the content can no longer be guaranteed. The characteristics and tactics of predatory journals (and meetings) have been previously delineated [5-7], however, this does not mean that they are always identified as such, and the implications for the general public, forensic practitioners, academia and courts when confronted by inaccurate and potentially spurious material are disturbing [8]. The opportunity for academic deception is also enhanced, as is the possibility of falsely increasing parameters, such as the h-index, that are routinely used to assess academic standing [9] (although this bibliometric indicator is not without its critics $[10,11])$.

Pre-print services have also added to the speed with which un-refereed material may be made widely available. These provide rapid (often within $24 \mathrm{~h}$ ) dissemination of raw findings and data sets that have not undergone peer review. Concerns have, however, been raised that they "cannot be considered as reliable sources of information" and that they may cause "poor science and unscholarly work to enter mainstream literature" $[12,13]$. Registering such material on research databases merely serves to bolster their credibility. 
Fig. 1 The Editor in Chief of Forensic Science Medicine and Pathology (from 2008-2021), Prof Roger Byard, with his dog Lucy

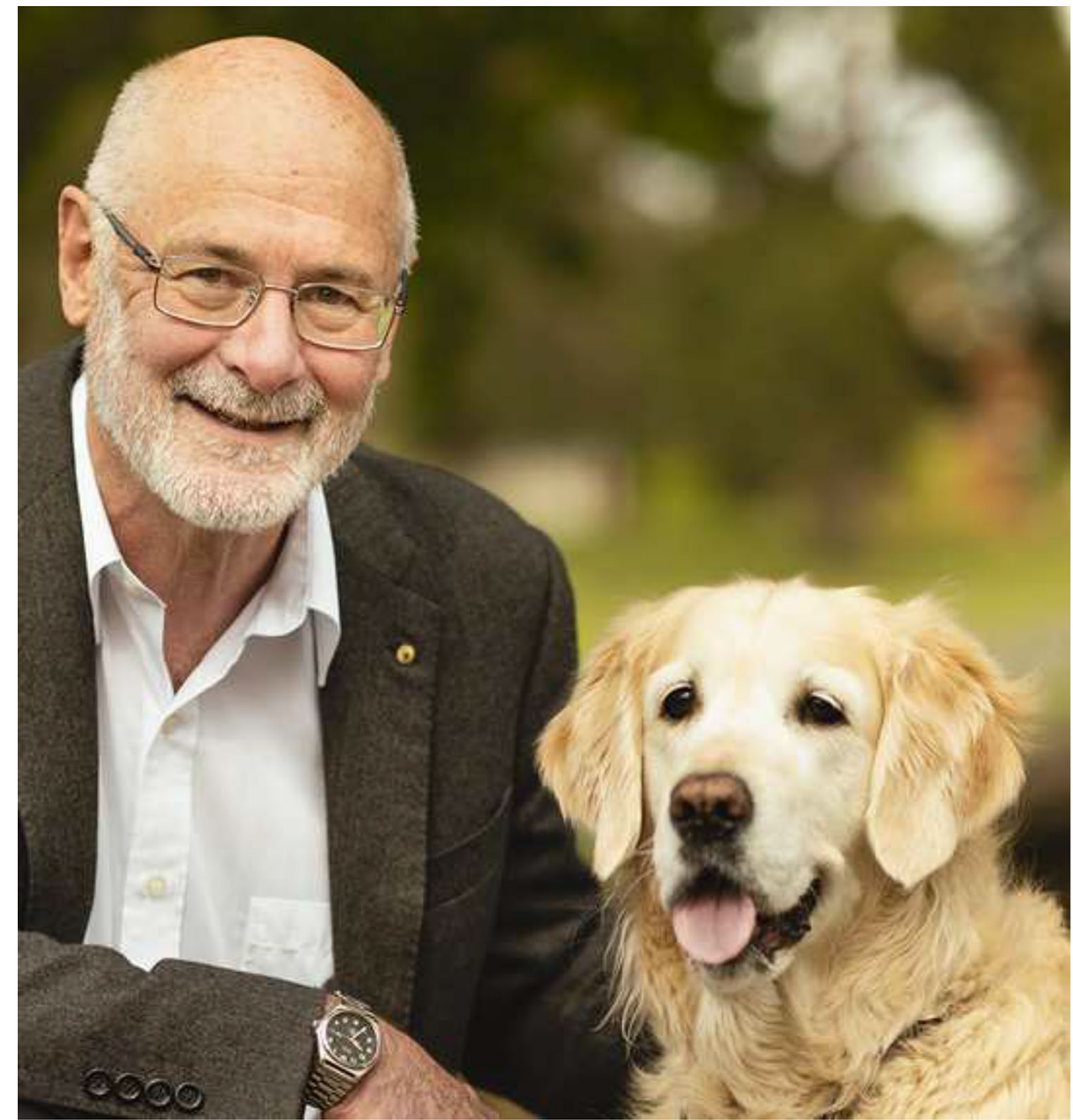

Although criteria have been set out that quite clearly specify when authorship should be granted, which include substantial contributions to the work and involvement with drafting and revising the manuscript [14], these are not always followed. This is particularly the situation with so-called "mega-authorship" papers, which may have literally hundreds of authors [15]. These types of papers can quite quickly give the impression of considerable academic standing to individuals who may have been very peripheral to performing, crafting and analyzing the research. While multiple contributors may be required for research projects that require large case numbers or material from multiple institutions, perhaps a better way of dealing with this would be acknowledgements rather than authorships? Alternatively, perhaps a "dual" indexing system would be useful separating publications with less than 10 authors for those with 10 and above. The first index would provide a more accurate evaluation of individual work, while the second would provide a measure of collaborative participation rather than direct contribution, as defined by the International Committee of Medical Journal Editors (ICMJE) [14].
So, as with many areas of academia nowadays the boundaries are constantly shifting. Perhaps one way of reducing the impact of predatory journals and preprint "publications" on perceived academic standing would be to ensure that only appropriately peer-reviewed material is accepted by online databases. In addition, rather than "mega-authorships" perhaps "mega-acknowledgements" would be a more accurate way to denote contributions? What is required are more transparent and appropriate measures of substantive individual scholastic activities so that true academic standing can be more appropriately assessed and recognized.

\section{References}

1. Kennedy D. Forensic science: oxymoron? Science. 2003;302:1625.

2. Byard RW, Tsokos M. Research, publishing, and forensic pathology. Forensic Sci Med Pathol. 2005;1:237-8.

3. Byard RW. Forensic text books - how to publish and perish, all at the same time. Forensic Sci Med Pathol. 2015;11:111-2. 
4. Byard RW. Academic referencing - a lost art. Forensic Sci Med Pathol. 2021;17:1-2.

5. Kearney MH. Predatory publishing: what authors need to know. Res Nurs Health. 2015;38:1-3.

6. Bartholomew RE. Science for sale: the rise of predatory journals. J R Soc Med. 2014;107:384-5.

7. Happe LE. Distinguishing predatory from reputable publishing practices. J Man Care Spec Pharm. 2020;26:956-60.

8. Yeo-The NSL, Tang BL. Wilfully submitting to and publishing in predatory journals - a covert form of research misconduct? Biochem Med (Zagreb). 2021;31:030201.

9. Byard RW. The forensic implications of predatory journals. Forensic Sci Med Pathol. 2016;12:391-3.

10. Koltun V, Hafner D. The h-index is no longer an effective correlate of scientific reputation. PLoS One. 2021;16:e0253397.

11. Waltman L, van Eck NJ. The inconsistency of the h-index. J Am Soc Inf Sci Tech. 2012;63:406-15.
12. Teixeira da Silva JA. Preprints should not be cited. Curr Sci. 2017;113:1026-7.

13. Teixeira da Silva JA. Preprints: ethical hazard or academic liberation? Kome. 2017;5:73-80.

14. Recommendations for the Conduct, Reporting, Editing, and Publication of Scholarly Work in Medical Journals. Updated December 2019. http://www.icmje.org/icmje-recommendations.pdf. Accessed 25 November 2021.

15. Byard RW, Vink R. Does listing of individual contributions in "mega-authorship" papers always follow best practice guidelines? Forensic Sci Med Pathol. 2021;17:545-6.

Publisher's Note Springer Nature remains neutral with regard to jurisdictional claims in published maps and institutional affiliations. 